Yorick J. de Groot Jan Bakker

Eelco F. M. Wijdicks

Erwin J. O. Kompanje

\section{Imminent brain death and brain death are not the same: reply to Verheijde and Rady}

Accepted: 6 August 2010

Published online: 16 September 2010 (C) The Author(s) 2010. This article is published with open access at Springerlink.com

Dear Editor,

Verheijde and Rady [1] suggest, referring to our recent article in Intensive Care Medicine [2], that imminent brain death (IBD) expands the pool of brain death (BD) for heartbeating organ donation (HBD). This statement is incorrect. As we stated, IBD "should not be considered equivalent to brain (stem) death and that the designation of a patient with IBD represents no more than a certain risk estimate" to become BD. However, BD patients can be included in the pool of IBD patients following our strict definition, which states that only patients who are "... with irreversible catastrophic brain damage of a known origin..." are considered to be in a state of IBD. Verheijde and Rady mention that IBD patients are not suitable for organ donation, as IBD patients may die several hours to days following withdrawal of mechanical ventilation. However, IBD patients may deteriorate, despite the most aggressive treatment of pathologically raised intracranial pressure (ICP), into a state of $\mathrm{BD}$.
Most patients fulfilling the criteria for IBD will die within an hour after withdrawal of mechanical ventilation and when a patient is determined BD, the view of Verheijde and Rady is no longer tenable. IBD is, as clearly

described by us in our article, a risk estimate and not a decision tool to withdraw life support. Verheijde and Rady worry about the harmful and painful procedures after the determination of IBD but that ignores the severity of the injury and IBD patients are deeply comatose, many irreversibly so. Because of its importance, we stated in our original article: "treating-limiting decisions remain the responsibility of the clinician who should base his decisions as much as possible on evidencebased risk estimates, taking opinions of relatives and autonomy of patient into account". This is in clear contradiction with the second, third, and fourth statement made by Verheijde and Rady.

One of the goals of IBD was to provide the clinician with a tool for early recognition of a potential organ donor (POD). Even initial contact with an organ donation procurement agency does not absolve the clinician of the duty to treat the patient. The decision to pursue aggressive medical or neurosurgical management and the decision to consider organ donation are totally independent of each other and always have been. The letter by Verheijde and Rady, however, is also a jeremiad against all that is wrong about BD determination. The last statement "some clinicians reject scientific evidence disproving the very concept of $\mathrm{BD}$ as equivalent to death" is odd and factually incorrect. It will be hard to find a physician closely involved with BD determination and organ donation who does not think these PODs are dead. Finally, we should correct Verheijde and Rady's historical inaccuracy claiming that Beecher coined the term "brain death". It was Schwab, who presented his triad for certifying brain death at the 16th annual meeting of the American Electroencephalography Society in 1962 [3].

Open Access This article is distributed under the terms of the Creative Commons Attribution Noncommercial License which permits any noncommercial use, distribution, and reproduction in any medium, provided the original author(s) and source are credited.

\section{References}

1. Verheijde JL, Rady MY (2010) Conversion of catastrophic neurological injuries to heart-beating organ donation. Intensive Care Med. doi:10.1007/ s00134-010-1967-5

2. de Groot YJ, Jansen NE, Bakker J, Kuiper MA, Aerdst S, Maas AIR, Wijdicks EF, van Leiden HA, Hoitsma AJ, Kremer HPH, Kompanje EJO (2010) Imminent brain death: point of departure for potential heart-beating organ donation. Intensive Care Med 36:1488-1494

3. Schwab RS, Potts F, Mathis P (1963) EEG as an aid in determining death in the presence of cardiac activity. Electroencephalogr Clin Neurophysiol $15: 147$

Y. J. de Groot · J. Bakker .

E. J. O. Kompanje (

Department of Intensive Care Medicine, Erasmus MC University Medical Center, P.O. Box 2040, 3000 CA Rotterdam,

The Netherlands

e-mail: e.j.o.kompanje@erasmusmc.nl

E. F. M. Wijdicks

Division of Critical Care Neurology, Mayo Clinic, Rochester, MN, USA 